\title{
Extra-Anatomic Bypass to the Distal Profunda Femoris Artery Using Autogenous Graft
}

\section{Queiroz AB, Ronald José Ribeiro Fidelis, Eutimio Aires Brasil, Cícero Fidelis and José Siqueira}

Vascular and Endovascular Surgery Department, Hospital Ana Nery, Universidade Federal da Bahia, Brazil

\section{Corresponding author: Queiroz $A B$}

$\equiv$ andrebrito01@hotmail.com

Vascular and Endovascular Surgery Department, Hospital Ana Nery, Universidade Federal da Bahia, Brazil.

Tel: 5511 3069-6101

Citation: Queiroz AB, Fidelis RJR, Brasil EA, et al. Extra-Anatomic Bypass to the Distal Profunda Femoris Artery Using Autogenous Graft. J Vasc Endovasc Surg. 2017, 2:1.

Received: January 21, 2017; Accepted: February 23, 2017; Published: February 28, 2017
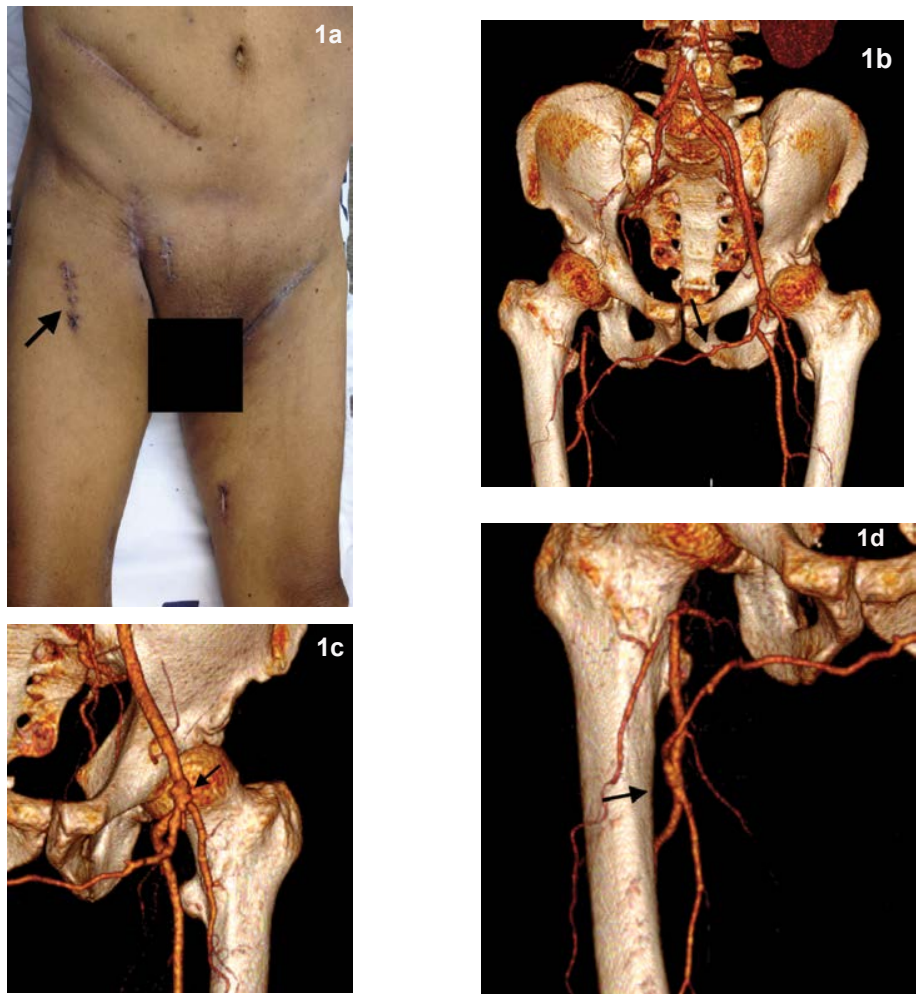

Figure 1 (a) Image shows numerous scars. The arrow shows the site of access to the profunda femoris artery. (b) Image shows the occlusion of the right external iliac, common and superficial femoral arteries. The arrow shows the extra-anatomic bypass using the great saphenous vein to the distal profunda femoris artery. (c) Detail of the proximal anastomosis (arrow) between the left common femoral artery and the great saphenous vein. (d) Detail of the distal anastomosis (arrow) between the great saphenous vein and the distal right profunda femoris artery. 


\section{Distal Profunda Femoris Artery}

Initial attention to the surgical importance of the Profunda Femoris Artery (PFA) in the revascularization of ischemic limbs was brought to light more than fifty years ago by Leeds and Gilfillan [1]. Since then PFA has been an important option for lower limb revascularization and limb salvage. In patients who had been submited to multiple previous operations, surgical access to the groin may be hampered by scarring and sometimes by local infection. Therefore, access to the distal PFA may be needed when there is lack of usual distal runoff $[2,3]$.

We present the case of a 62-year-old man with a history of progressive gangrene of the right forefoot. The patient had occlusion of the right iliac and common femoral arteries and had undergone several operations in the last eight months. First, he had been submitted to an iliac-femoral endarterectomy, followed by a thrombectomy few days later. It was not successful and he was submitted to a common iliac to PFA bypass using a prosthetic graft. Few days later, due to a severe infection the graft was removed and a common iliac to poplitea artery bypass was performed using the ipsilateral great saphenous vein.
After two months, the patient was admitted with occlusion of the later bypass, presenting with cyanosis and coldness in the right lower limb until the proximal thigh. Taking into consideration the large number of surgical scars (Figure 1a) and the occlusion of both the common and superficial femoral arteries, we decided for performing an extra-anatomic bypass from the left commom femoral artery to the distal right PFA.

The left great saphenous vein was harvested trough short separated skin incisions. Valvulotomy was performed with the aid of a Mills valvulotome and the vein was used in a nonreversed way to a much better size match at the anastomotic sites. The distal PFA was accessed trough an anterolateral approach and the graft were positioned in a subcutaneous tunnel in the pubic region and below the sartorius muscle in the thigh. Because the extension of gangrene the revascularization was followed by a below knee amputation. An angiotomography with 3D reconstruction at 6-month follow-up showed the patency of the graft (Figure 1b) and details the proximal (Figure 1c) and distal anastomosis (Figure 1d). The patient had an uneventful recovery and one year later was rehabilitated using prosthesis. 


\section{References}

1 Leeds FH, Gilfillan RS (1961) Importance of profunda femoris artery in the revascularization of the ischemic limb. Arch Surg 82: 25-31.

2 Nunez AA, Veith FJ, Collier P, Ascer E, Flores SW, et al. (1988) Direct approaches to the distal portions of the deep femoral artery for limb salvage bypasses. J Vasc Surg 8: 576-581.

3 Ouriel K, DeWeese JA, Ricotta JJ, Green RM (1987) Revascularization of the distal profunda femoris artery in the reconstructive treatment of aortoiliac occlusive disease. J Vasc Surg 6: 217-220. 